\title{
Preface for the Mary C. McKenna Honorary Issue of Neurochemical Research
}

\author{
Arne Schousboe $^{1}$
}

Published online: 9 January 2017

(C) Springer Science+Business Media New York 2017

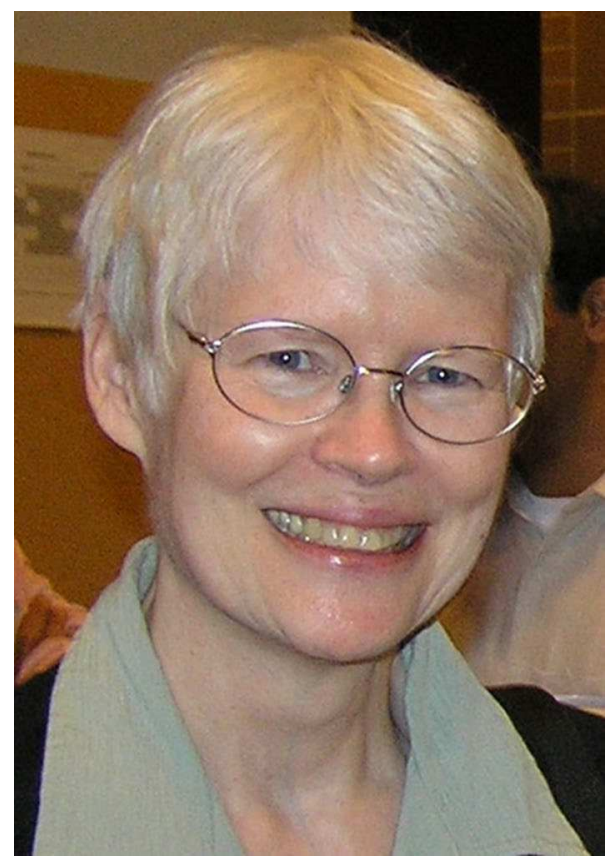

This special issue of Neurochemical Research contains manuscripts from a large number of investigators throughout the world to honor Mary C. McKenna for her contributions to the understanding of glutamate metabolism in brain and her leadership in the field of brain energy metabolism.

It is not surprising that when Mary's parents noted her curiosity at a young age that led to dissecting clams at the

Arne Schousboe

arne.schousboe@sund.ku.dk

1 University of Copenhagen, Copenhagen, Denmark beach, cutting open a golf ball to see what was inside, collecting snakes and caterpillars, and causing her friend's family to exit the house after she and her good friend Georgia mixed up creations with a chemistry set, they saw this as a sign that she would likely become a scientist. Mary did her thesis research on the effects of essential fatty acid deficiency on brain development and myelination in the laboratory of the noted myelin neurochemist, Dr. Tony Campagnoni when he was a young assistant professor at University of Maryland at College Park. Her enzyme kinetics class was taught by Dr. David Martin a neurochemist known for 
his research on the GABA synthesizing enzyme, glutamate decarboxylase (GAD). Mary met John Edmond when she was applying for postdoc positions, and although she was unable to relocate to Los Angeles due to geographical constraints, she and John Edmond became lifelong friends. After a postdoctoral fellowship at NIH studying vitamin A and fatty acid metabolism, Mary returned to the field of neurochemistry when in November 1982 she joined Dr. J. Tyson Tildon's research group in the Department of Pediatrics at University of Maryland School of Medicine. Mary stayed at the School of Medicine and is currently a tenured full Professor in the Department of Pediatrics and Program in Neuroscience.

Her early studies with Tyson Tildon fueled Mary's interest in the field of brain energy metabolism. Her early research on metabolism was influenced by the work of Leif Hertz, Arne Schousboe, Arthur Cooper, Marc Yudkoff, Tyson Tildon, John Clark, Jim Lai, Gary Gibson, John Blass and other leaders in the field of energy metabolism. Actually, I had the pleasure of meeting Mary at ASN Meetings during this early period of her career. The importance of energy metabolism was underestimated by many neuroscientists in the late ' 80 s and early ' 90 s, due to a perception that everything was already known. The increasing evidence that most forms of neurodegeneration are associated with energy failure helped to spur interest in the field; however, it was sometimes a struggle to get metabolism on the program at meetings. The application of ${ }^{13} \mathrm{C}-\mathrm{NMR}$ to studies of brain revolutionized the field of energy metabolism and gave investigators the tools to perform ex vivo studies of metabolism in brain and in vitro studies with primary cultures of astrocytes and neurons. The use of these tools led to new insights and a more in depth understanding of cellular and subcellular compartmentation in brain and metabolic trafficking between astrocytes and neurons. Clearly, Mary has played a fundamentalrole in this field of research as attested in the short review by Schousboe [1] in this issue of Neurochemical Research.

Attending the ISN meeting in Sydney, Australia was a pivotal point in Mary's career. One reason was the poster presentation by Niels Westergaard, Ursula Sonnewald and Arne Schousboe in which results from one of the first ${ }^{13} \mathrm{C}$ NMR studies of glutamate metabolism in astrocytes were presented. Mary and John Edmond both spoke in the excellent session on metabolism chaired by Bernd Hamprecht, but to their frustration this was the only session on metabolism on the program at the meeting. During the session break and later at dinner Mary, John and Bernd decided to organize a meeting on energy metabolism as a satellite meeting to the 1993 ISN Meeting in Montpelier, France. The organizing committee of this first Brain Energy Meeting was expanded to also include John Clark, Leif Hertz, Richard Shank and Tyson Tildon. This highly successful, interactive conference was held in the historical walled city of Carcassonne, France and energized the community of investigators in the field of brain metabolism, and I was fortunate enough to be invited to that first Brain Energy Meeting. Mary organized the 3rd ICBEM (International Conference on Brain Energy Metabolism) meeting in Waterville Valley, $\mathrm{NH}$ and has been involved in organizing all of these meetings to date. I have played a key role in organizing these meetings since 1997, and Mary and I have edited seven of the special issues from these meetings. Mary is rightfully proud that the ICBEM meeting series has continued, with the most recent 12th ICBEM meeting held in 2016 in Hong Kong, and the 13th conference planned for Valdivia, Chile in 2018. Most neuroscientists now recognize the importance of metabolism in brain function, and it has become generally accepted that impaired metabolism and/or metabolic failure is a key feature of most, if not all, forms of neurodegeneration. Thus, it is difficult for young investigators to understand what a struggle it was to get metabolism onto the program at meetings just a few decades ago. Technological advances, most particularly the use of ${ }^{13} \mathrm{C}$-NMR spectroscopy and GC-MS have expanded the capacity to study and understand cell specific metabolism and the dynamic bi-directional metabolic trafficking between neurons and astrocytes in brain. One of Mary's most important contributions has been her role in helping to insure that metabolism is on the program of the ASN meetings as well as other meetings.

Regulation of metabolism and compartmentation in brain have always been fascinating to Mary. She was delighted when shortly after the first ICBEM meeting in Carcassonne she and Ursula Sonnewald obtained a NATO Collaborative Research Grant. This collaboration led to their paradigm changing study demonstrating that the metabolic fate of glutamate in astrocytes was regulated by its concentration in the extracellular milieu (see Schousboe [1] for references). This was a critical study as it explained why investigators using similar techniques with rats and mice found large differences in the metabolic fate of glutamate. This study, which has been cited 269 times, settled a controversial issue in the field, namely that there might be species differences in brain glutamate metabolism. Mary has continued to focus much of her research on compartmentation and metabolism of alternative substrates in brain. More recently she has studied metabolic alterations in clinically relevant developmental brain injury models including fragile $\mathrm{X}$ syndrome, neonatal hypoxia-ischemia, and pediatric traumatic brain injury and neuroprotection of developing brain. Mary was an editor for the first two special issues ever published on Pediatric Traumatic Brain Injury [2, 3]. It should be added in this context that I have had the pleasure of writing several manuscripts with Mary and in some cases this has been done while staying with her and 
her wonderful husband at their charming A-frame house in 5 acres of trees in Howard County Maryland. Working closely with Mary on a manuscript for several days is an experience that I have appreciated very much. She does not stop editing a manuscript text until it is logical and understandable to experts as well as those new to the field.

Mary was initially reluctant to assume the responsibility of writing the chapter on Energy metabolism for the 7th edition of the Basic Neurochemistry textbook. She notes that she could not have taken the chapter from Lou Sokoloff's focus on PET scanning to compartmentation and NMR spectroscopy without co-authors including Ursula Sonnewald, Arne Schousboe, Helle Waagepetersen and Rolf Gruetter. All of the authors were delighted when they heard that that Lou Sokoloff told editor George Siegel that he thought the 2006 chapter was "terrific" [4]. It should be noted that later up-dates of this textbook chapter have involved Gerry Dienel as co-author [5].

Early in her career Mary was active in the American Society for Nutritional Sciences and served on the FASEB Meetings Committee and the Excellence in Science Award Committee. For the past 3 decades she has been very actively involved the American Society for Neurochemistry, having served two separate terms on the Council, and served as Secretary of ASN from 1999 to 2001. Throughout her career she has served on numerous ASN and ISN program committees and organized many sessions for the annual meetings. Mary also served on the International Society for Neurochemistry Council from 2003 to 2007 and was the Intersociety liaison between ASN and ISN.

Mary has an international reputation for research excellence and leadership in the field of brain energy metabolism. She currently serves as Associate Editor/Senior Editor/Handling Editor for the Journal of Neurochemistry, Journal of Neuroscience Research, ASN NEURO, and Frontiers in Neuroenergetics. She is a member of 7 other editorial boards including the Journal of Cerebral Blood Flow and Metabolism, Developmental Neuroscience, Metabolic Brain Disease, International Journal of Developmental Neuroscience, Neurochemical Research, Frontiers in Nutrition and Advances in Neurobiology.

Mary really enjoys teaching and mentoring young scientists and clinicians and explaining science to the public. Since 2013 she has been in charge of the section on Energy Transduction and Biochemical Integration for the graduate program core course taken by all first year graduate students. She enjoyed giving lectures on the TCA cycle, and electron transport and respiration at University of Copenhagen in 2009 and teaching a special course on using ${ }^{1} \mathrm{H}$ and ${ }^{13} \mathrm{C}$-NMR spectroscopy to study brain metabolism at University of Alaska, Fairbanks in 2003. Mary notes that one of the most fulfilling aspects of her career has been mentoring and interacting with students and young scientists and helping them succeed in their careers. She has had the honor to serve as an external examiner for ten doctoral thesis defenses in Canada, Norway and Denmark. Mary has commented many times that the quality of the doctoral candidates and the students at the ICBEM meetings are outstanding and she is happy that the future of brain energy metabolism is in the hands of such capable and talented young investigators.

When she is not busy with grants, papers or meetings Mary enjoys summer vacations with her husband Alan and son John on Topsail Island, NC, designing quilts, gardening, growing organic vegetables and traveling, including fun adventures like paragliding in Switzerland and zip lining in Vancouver. Mary's travels have taken her to every continent except Antarctica, and she is looking forward to the ICBEM meeting in Valdivia, Chile in 2018.

Arne Schousboe

Guest Editor

\section{References}

1. Schousboe A (2017) A tribute to Mary C. McKenna: glutamate as energy substrate and neurotransmitter-functional interaction between neurons and astrocytes. Neurochem Res 42:1-6

2. Robertson C, McKenna MC (2006) Pediatric Traumatic brain injury: from molecular mechanisms to clinical research. Dev Neurosci 28(4-5):239-478

3. McKenna MC, Noble-Haeusslein LJ, Robertson CL (2010) Pediatric traumatic brain injury: update 2010 - from basic research to clinical practice. Dev Neurosci 32(5-6):329-524

4. McKenna MC, Gruetter R, Sonnewald U, Waagepetersen HS, Schousboe A (2006) Energy metabolism of the brain. In: Siegel G, Albers W, Brady S, Price D (eds) Basic neurochemistry 7th edn. Elsevier, London, pp 531-557

5. McKenna MC, Dienel GA, Sonnewald U, Waagepetersen HS Schousboe A (2012) Energy metabolism of the brain. In: Brady S, Siegel GJ, Albers RW, Price D. (eds) Basic neurochemistry: principles of molecular, cellular and medical neurobiology, 8th edn. Academic Press, Burlington, pp 200-231 